\title{
La posmodernidad purulenta
}

Revisión de la revista La PUSmoderna como espacio de confluencia y disgregación, 1989-1997

The Purulent Postmodernity: Revisiting the Magazine La PUSmoderna as a Space of Cultural Confluence and Disintegration, 1989-1997

José Luis Paredes Pacho

\section{OpenEdition}

\section{Journals}

Edición electrónica

URL: http://journals.openedition.org/transtexts/1308

DOI: 10.4000/transtexts.1308

ISSN: $2105-2549$

\section{Editor}

Gregory B. Lee

\section{Referencia electrónica}

José Luis Paredes Pacho, «La posmodernidad purulenta », Transtext(e)s Transcultures 跨文本跨文化 [En ligne], 14 | 2019, mis en ligne le 31 décembre 2019, consulté le 28 juillet 2020. URL : http:// journals.openedition.org/transtexts/1308; DOI : https://doi.org/10.4000/transtexts.1308

Este documento fue generado automáticamente el 28 julio 2020.

(c) Tous droits réservés 


\section{La posmodernidad purulenta}

Revisión de la revista La PUSmoderna como espacio de confluencia y disgregación, 1989-1997

The Purulent Postmodernity: Revisiting the Magazine La PUSmoderna as a Space of Cultural Confluence and Disintegration, 1989-1997

José Luis Paredes Pacho

...convertir la sensación de carencia en gesto.

La era de la discrepancia ${ }^{1}$

In turn, the paper accelerated the growth and development of the community that birthed it.

John McMillan²

Aparece la risa en medio del caos.

Oliver Debroise ${ }^{3}$

\section{Lugar de encuentro y reventón}

1 El primer número de la revista La PUSmoderna salió a la venta en noviembre de 1989, y el número 8, el último, apareció en 1997. La PUSmoderna fue la continuación de una revista previa llamada La Regla Rota ${ }^{4}$ ambas editadas por el periodista y fotógrafo Rogelio Villarreal, casi siempre de la mano del caricaturista Ramón Sánchez Lira, conocido como Mongo.

2 Al servir como un sitio de encuentro entre artistas, escritores, promotores y músicos (muchos de los cuales cobraron importancia nacional e internacional a finales de los años noventa), La PUS fungió como lugar de diseminación de su producción, pero también marcó el comienzo de la disgregación de una escena, su bifurcación o disolución en posturas estéticas posmodernistas y postconceptualistas. Asimismo, registró un cambio en las prácticas de gestión por parte de los productores culturales, quienes parecían dejar atrás las formas de operar propias de la escena subterránea de los ochenta, para pasar hacia lo que Gerald Raunig llama "instituciones proyecto", ${ }^{5}$ insertas ya en sistemas globalizados. 
3 Este trabajo considera a La PUSmoderna no sólo como un medio de circulación de información, sino como un espacio en sí mismo. Como hipótesis sostiene que la revista La PUSmoderna puede ser estudiada como un espacio de articulación de las escenas subterráneas en el periodo de 1989 a 1997, un lapso en el que tuvo lugar la apertura de otros sitios independientes relacionados con el arte, como Curare, Espacio Crítico para las Artes (1991) y la Galería de Autor Pinto Mi Raya (1989), o lugares de encuentro, creación, fiesta y exhibición alternativos a los oficiales como La Quiñonera (arranca como espacio de exhibición con Roberto Escobar en 1988, hasta su fallecimiento en 1991), El Salón de los Aztecas (1988), Mels's Café (1990), InSitu (1990), Temístocles 44 (1993), Zona (19931995), entre otros, hasta llegar a La Panadería (1994), que marca ya el paradigma de la nueva época por su forma de vincularse con los circuitos globales.

Este enfoque se refuerza si recordamos que la revista organizaba fiestas semanales en el bar gay Disco Bar Nueve, articulando ahí un punto más de socialización y diseminación. En este sentido, la experiencia de La PUSmoderna está emparentada con el surgimiento de diversos lugares de ocio vinculados a diversas escenas culturales desde el arte y, por supuesto, al rock, entonces estigmatizado: La Rockola (surgida aproximadamente 1982), Rockotitlán (1985), El Tutti Fruti (1985) y el foro multidisciplinario La Última Carcajada de la Cumbancha, mejor conocida como LUCC (1988). Los foros mencionados representaron otra experiencia de vida nocturna distinta a la convencional, por estar relacionados con las escenas culturales emergentes y pueden considerarse como antecesores de la apertura de espacios vinculados a las nuevas posturas de las artes visuales de la década de los noventa, también en la capital mexicana, como La Panadería (1994-2002), fundada por Miguel Calderón y Yoshua Okon, o bien Art Deposit (1995). ${ }^{6}$

\section{Escenas subterráneas}

El ámbito cultural en el que se desarrolló La PUSmoderna es caracterizado en este trabajo como escena subterránea, entendida como una red de circuitos de producción y diseminación cultural marginales respecto a los circuitos oficiales, no subsidiados o apadrinados por el Estado, así como distantes del gran mercado y de las grandes industrias culturales de la época.

6 No es una caracterización estética ni estilística, sino que pretende codificar las formas específicas de operar culturalmente en el periodo. ${ }^{7}$ Estas formas de operar se basaban sobre todo en la colaboración mutua a través de amplias redes sociales (conectadas todavía presencialmente, desde luego), regidas muchas veces por la economía informal, y llevadas a cabo fuera de los espacios culturales institucionales o convencionales. Sólo en ocasiones buscaban becas y premios oficiales o patrocinios privados $y$, en este sentido, hablar de cultura o escena subterránea tampoco supone situaciones de marginalidad o de autonomía completamente puras.

7 Prefiero esta caracterización a la de contracultura, porque esta última categoría tiene un sobrecargado sentido de época y, por lo mismo, suele estar relacionada con estilos de comportamiento, de vestir y hablar, así como con ciertas narrativas, referidas casi siempre a los años sesenta, o a las experiencias comprendidas desde la bohemia de la generación beat, hasta el hippismo. 


\section{Linajes de LaPUS}

8 ¿Revista cultural? ¿Revista de rock, de cultura subterránea, contestataria, contracultural o revista de artista? ¿Cuál es la tradición en la que se inserta $L a$ PUSmoderna? Si bien podríamos establecer características que la emparentarían con la emblemática tradición de las revistas subterráneas estadounidenses, La PUSmoderna no reivindicó explícitamente ningún legado al respecto. Un linaje que sí asumió expresamente fue el de la vanguardia mexicana de los estridentistas, quienes fueron mencionados varias veces en esa revista, al igual que en La Regla Rota (esta última publicó en 1987 un artículo del estridentista German List Arzubide sobre Jorge Luis Borges. ${ }^{8}$ De hecho, List Arzubide fue invitado en 1984 a la presentación del primer número de esta revista). ${ }^{9}$

9 También podríamos emparentar a La PUSmoderna con la actitud antiacadémica de los infrarrealistas, quienes expresaron una forma de ver y vivir el centro de Ciudad de México de los años setenta, equivalente a la que sería plasmada en La PUSmoderna para los años ochenta y noventa. Los infrarrealistas jamás fueron mencionados en $L a$ PUSmoderna, pero llegaron a publicar Correspondencia infra $(1976),{ }^{10}$ revista ilustrada por la artista Carla Rippey, quien sí colaboraría recurrentemente en La Regla Rota y La PUSmoderna.

10 Como precedentes dentro del campo de las artes visuales, podemos referirnos al colectivo No-Grupo (1977-83) por su postura paródica y antisolemne, no doctrinal, con una estética urbana y callejera. Al respecto, Mónica Meyer publicó una nota sobre Rubén Valencia, y el No-Grupo, en La PUSmoderna número 2 (1990), en la cual destaca el sentido del humor del colectivo, "su irreverencia total y su desprecio por la solemnidad, así como la utilización de elementos tanto del arte culto como del kitsch popular". ${ }^{11}$ Por otro lado, un antecedente evidente fue Peyote y Compañía (1973), agrupación que sostuvo posturas igualmente callejeras, humorísticas y claramente localistas (que algunos llamaron neomexicanistas), ${ }^{12}$ parecidas a las de La PUS; además de que Rogelio Villarreal y Ramón Sánchez Lira participaron en sus acciones.

11 Dentro del ámbito del rock, tanto La Regla Rota como La PUSmoderna tuvieron claras coincidencias con el grupo de rock Botellita de Jerez, surgido en 1983, el cual utilizó el humor como crítica cultural en forma de autoparodia mexicana, tanto en su música como en su paramusicalidad. De hecho, La Regla Rota número 2 (1984) publicó una entrevista de Víctor Roura a este grupo ${ }^{13}$ y el número 4 de La Regla Rota (1987) presentó un artículo de Pedro Nudelman que, al describir el trabajo de Botellita, destacó temas que coinciden con los intereses y perspectivas de las dos revistas: "El humor de los botellos consiste en introducir al foro la variedad de referencias culturales que todo roquero de esta ciudad trae a cuestas [...] como son las esquinas con sus tragafuegos, los concheros ${ }^{14} \mathrm{y}$ los subempleados; la cultura del Alarma! ${ }^{15}$ el albur ${ }^{16}$, y El Santo, ${ }^{17}$ la música olvidada por los jóvenes a causa de la insuperada 'brecha generacional', como el mambo, el son, la ranchera y todo el look kitsch mexicano (art nacó)". ${ }^{18}$

12 En el campo editorial roquero, debemos mencionar como antecedente a la revista Piedra Rodante de los setenta, sin embargo La PUS nunca se consideró a sí misma como una revista contracultural. De hecho, Rogelio Villarreal se desvinculó reiteradamente de las revistas contraculturales mexicanas. Durante una entrevista con Carlos Martínez Rentería, Villarreal negó cualquier vinculación de sus revistas con el espíritu de los sesenta y setenta: "no me parece que haya mucha relación entre revistas de los setenta 
como Yerba, La Piedra Rodante o El Corno Emplumado y revistas como La Regla Rota, Moho o La PUSmoderna". ${ }^{19}$

13 Si bien Villarreal renegó de la contracultura, sí prefirió emparentarse con la infinidad de fanzines que proliferaron en la ciudad de México durante los años ochenta y noventa. En 2001 declaró que "La Regla Rota fue más bien un megafanzine, por el papel y por su diseño", ${ }^{20}$ sin embargo se trata de un comentario retrospectivo, ya que los fanzines no fueron una referencia para concebir La Regla Rota ni La PUSmoderna, pues ni siquiera hay indicios de que Villarreal los conociera cuando comenzó a publicar su primer revista en $1984 .{ }^{21}$ Sería hasta arrancar los años noventa que Villarreal se vincularía con algunos fanzines, tanto de clase media como de barrio bajo; por ejemplo, el fanzine punk Puro Pinche Ruido (editado por punks de barrio bajo). Es importante asentar que ciudades como Tijuana y Guadalajara tenían sus propias escenas con publicaciones marginales, como La Banda Elástica en Tijuana, o en Guadalajara la revista Galimatías y los fanzines El Tamal de Acero y Corazón de Pollo, ¡Los de Abajo!, Los Hijos de la Chingada, etc. En realidad, los fanzines constituyeron por sí mismos una escena que se expandió por sus propios medios a fines de los ochenta, al margen de las revistas de la capital del país. ${ }^{22}$

14 En cuanto al cómic, podemos remitirnos al concepto de "Cómic-arte" de Zalathiel Vargas, ${ }^{23} \mathrm{o}$ bien, a las Fábulas Pánicas del propio Jodorowsky, publicadas en el diario $\mathrm{El}$ Heraldo de México, así como a los Psicogramas de este último artista, en los que participaron René Rebetez, Luis Urías y Felipe Ehrenberg (este último sería colaborador de La PUSmoderna y asiduo concurrente a las noches del jueves en el Bar Nueve). Y ya que mencionamos a Jodorowsky, La PUSmoderna reflejaba una noción de la experiencia artística vinculada a la fiesta, ${ }^{24}$ y quizá por ello podría emparentarse igualmente con la noción de "fiesta-espectáculo" de los efímeros de Jodorowsky, aunque debemos reconocer que la fiesta ("el reventón") fue una característica general del consumo cultural subterráneo en los ochenta y noventa mexicanos. ${ }^{25}$ Por último, podemos mencionar la publicación Sucesos para todos, revista amarillista que el artista chileno comenzó a dirigir alrededor de 1977, "para infiltrarse en los puestos de periódicos con las obsesiones hilarantes y sangrientas de la contracultura", ${ }^{26}$ donde tuvo como colaborador al fotógrafo Pedro Meyer, quien también participaría en La Regla Rota y en La PUSmoderna, además de que este fotógrafo asistiría frecuentemente al Bar Nueve.

La PUSmoderna y La Regla Rota cubrían varias disciplinas, asumiendo que existía un lector que se interesaba también por tan diversos campos. Villarreal postulaba que cada una de las prácticas culturales y disciplinas que publicaba era tan importante como la otra. La PUS pretendía inscribirse en una zona donde cada ámbito se encontraba con el otro, a veces fuera de cualquier sistema artístico. Tanto la reflexión y los ensayos, como la crítica cultural y de arte, la crónica y la poesía, eran presentados en igualdad de circunstancias y el diseño de la revista ofrecía una relación equitativa entre el texto, las fotografías y la gráfica.

Como referentes contemporáneos, La PUSmoderna reconocía la empatía con revistas de otras ciudades del país y del extranjero, como La Línea Quebrada, de Tijuana, así como Macho Cabrío, publicada en Lima, Perú. En alguna ocasión Villarreal habló sobre el parecido de La Regla Rota con estas dos revistas y, de paso, definió sus propias intenciones editoriales: "hemos enfrentado simultáneamente en Lima, México y Tijuana la necesidad de reunir varias áreas de la cultura en un mismo y antisolemne espacio, logrando así que los públicos de unas y otras -fotografía, cine, poesía, 
historieta, etc.-, tengan acceso a sus vecinos rompiendo la esquematización y los compartimentos con un vasto sistema de vasos comunicantes: en este caso, de papel". ${ }^{27}$

Así como Villarreal reconoció su cercanía con esas dos revistas de Tijuana y Lima, ni La Regla Rota ni La PUS se relacionaron nunca con revistas ibéricas análogas como La Luna de Madrid, o Sur Express, representativas de la "Movida Madrileña", a pesar de que Villarreal sí supo de su existencia. ${ }^{28}$ Sorprendentemente tampoco mencionó a las publicaciones underground de la contracultura de los años sesenta en Estados Unidos como Los Angeles Free Press, ${ }^{29}$ no obstante que sus revistas compartían varias características con aquellas publicaciones estadounidenses. Tampoco se ocupó de las revistas de artista, o revistas-objeto, extranjeras, como ya dijimos anteriormente. Detengámonos un momento en este aspecto.

no se inscribió en la tradición de las revistas de artista, inaugurada en la década de los sesenta por las publicaciones de Geroge Maciunas en Fluxus, y por revistas como Semina de Wallace Berman (1955-1974), dè-coll/age de Wolf Vostell (1962-1969), Aspen de Phyllis Johnson (1965?) o S.M.S. de William Copley (1968), a pesar de que en México existía una tradición equivalente (y con las que sin duda La PUS estaba en deuda). Y esto ni siquiera porque algunos de los protagonistas, como Magali Lara y Felipe Ehrenberg, participaron tanto en La Regla Rota, como en La PUSmoderna. Tampoco se reconoce cercana a experiencias como las revistas mexicanas Lacre y Paso de Peatones. De las pocas referencias a una revista de artista, mencionó en el número 6 de La PUS (1996), a Wee Wee de Armando Sarignana, Dulce María López Vega y José Medina, así como a Pelos de cola. Asimismo, en el número 4 (publicado en 1992), integró como corresponsales en Monterrey a los editores de la revista-objeto Fobia ${ }^{30}$ que ofrecía monos, neográficas, textos $y$ humor. Editada por un colectivo de Tamaulipas, cercanos a la escena de rock experimental de ese estado, cada ejemplar se entregaba en una caja que contenía a su vez bolsas de papel estraza que guardaban las colaboraciones y la gráfica.

La tradición estadounidense de revista de artista implicaba asumir a la revista bidimensional como un soporte para la experimentación, ya fuera convirtiéndolo en un espacio tridimensional o bien, explorando sobre su superficie bidimensional a la manera de Robert Smithson, quien realizaba aproximaciones al lenguaje poco ortodoxas, reivindicando ideas como "lenguaje para ver y/o cosas para leer", así como la noción de "material escultural" relacionado con el leguaje, entendido a su vez como "algo construido, no escrito". ${ }^{31}$ Pero La PUS no transgredió de esta manera el lenguaje escrito.

La PUS tampoco fue una revista-espacial, a la manera de la revista Aspen: Magazine in a box (1965-1971). ${ }^{32}$ Gwen Allen, autora del libro Artists' Magazines. An alternatuve Space for Art, relata cómo la revista entendida normalmente como un objeto doblado y bidimensional, se transformó con Aspen en un espacio expositivo-tridimensional. ${ }^{33}$ Aspen fue fundada por la periodista y editora Phillys Glick, (también conocida como Phyllis Johnson), quien la pensó originalmente como una publicación tridimensional dentro de una caja de cartón, empacando dentro de ella todo tipo de contenidos desencuadernados, incluyendo discos flexibles, películas, suvenires y otros objetos como borradores, piedras, semillas de flores silvestres, muestras de té, un libreto de ópera, viejos periódicos y rompecabezas.

21 Comparada con Aspen, La PUSmoderna nunca superó su carácter bidimensional ni su diseño estático y lo más cerca que estuvo a este tipo de prácticas conceptuales fue cuando incluyó un cubo para armar diseñado por Roberto Escobar. ${ }^{34}$ En otras palabras, 
La PUS fue formalmente innovadora sólo si se compara con las revistas mexicanas convencionales de aquella época, y esto sólo por su intencionalidad corrosiva, atrevida, bohemia, exaltadora de su propia precariedad. ${ }^{35}$

Si bien La PUSmoderna no experimentó con su propio soporte, sí registró la experimentación practicada dentro de las escenas y disciplinas que documentó. Escenas que compartían espacios sociales, informales o heterodoxos, donde cada ámbito disciplinario se familiarizaba con los otros: galerías domésticas, bares, centros nocturnos de baja estofa, exposiciones ocasionales, conciertos de rock y, desde luego, el ya mencionado Bar Nueve.

La PUSmoderna no sólo reflejó las escenas subterráneas sino que fue parte de las mismas. Sus páginas registraron y al mismo tiempo ayudaron a conformar y visibilizar a las escenas subterráneas en vías de construir sus propios circuitos, proceso que les conduciría a fines de los noventa a inscribirse en dinámicas de mercado estratificado, incluso de carácter global: festivales de rock, ferias de arte, festivales de cine, o galerías comerciales internacionalizadas. Dicho de otra forma, La PUS sí se constituyó como una revista que, ante la carencia de espacios de exhibición y escenificación en México, creó contexto y ambiente, además de que diseminó nuevas expresiones hacia círculos nuevos, más allá del mero gueto de cada ámbito o disciplina subterránea, convirtiéndose así en "un metafórico terreno extendido para el encuentro", ${ }^{36}$ a semejanza de las revistas conceptuales o de artista que describe Allen en su libro.

De acuerdo con Gwen Allen, las revistas de artista que surgen a mediados de los sesenta con Aspen y se prolongan hasta los años noventa, fueron de la mano con la evolución de la noción de espacio alternativo, ya que, para el arte conceptual el mismo término "alternativo" condujo hacia la noción de la "página impresa bidimensional" como sustituto del espacio expositivo; es decir, como "un corolario del interior arquitectónico de una galería o museo" ${ }^{37}$ Desde esta óptica, es congruente no desvincular a la revista La PUSmoderna del Bar Nueve, ya que cada jueves se convertía en un espacio real, "desplegable" de la revista, a la manera de una "revista espacial". En palabras de Allen, podríamos decir que La PUS también fue dos espacios de encuentro, uno metafórico y otro físico o arquitectónico; en ambos confluían artistas emergentes que terminarían por definir las prácticas artísticas y de producción cultural de las siguientes décadas.

Cuando Gwen Allen reseña la revista conceptual de poesía mimeografiada 0 to 9 , afirma que este tipo de publicaciones "estaban tan profundamente entretejidas con los espacios auténticos en los que los poetas interactuaban y socializaban que, en un sentido real, las revistas documentaban esos espacios tanto como ayudaron a producirlos". ${ }^{38}$ Podemos tomar esta aseveración para el caso mexicano, ya que muchos artistas, músicos, cineastas, directores de teatro o críticos de arte que asistían al Bar Nueve a reventar, también colaboraban con la revista. A su vez, en un juego de espejos, la revista documentaba esas noches del Bar Nueve mediante fotografías que publicaba con humorísticos pies de foto.

Si La PUSmoderna no experimentó con el soporte editorial hasta convertirlo en una extensión de la galería, ni buscó llevar un objeto bidimensional encuadernado hacia un espacio tridimensional de exhibición, como fue el caso de la revista Aspen, ${ }^{39}$ sí impulsó los objetivos prácticos e ideológicos de los espacios alternativos, entendidos por Allen como otros espacios de exhibición, no lucrativos y administrados por artistas, en la medida en que "las revistas desafiaban las instituciones y las economías del mainstream 
artístico, al apoyar nuevas formas experimentales de arte fuera del sistema comercial de galerías". ${ }^{40}$

27 La virtud del Bar Nueve y de las revistas de Rogelio y Mongo radicó en su capacidad para hacer confluir lo mejor y más vital de lo que sucedía fuera de los canales preestablecidos de ejercicio cultural de aquel momento, siendo ellos mismos, Villarreal y Sánchez Lira, unos pequeños promotores culturales independientes vinculados directamente con las escenas que convocaban. De esto sí tenían conciencia, de ahí la constante invitación extendida incluso a personalidades de generaciones anteriores, como el estridentista List Arzubide, o a Juan José Gurrola y Carlos Monsiváis, para que asistieran a sus fiestas o publicaran en sus páginas. Al mismo tiempo, si bien el núcleo era una comunidad de clase media, estas escenas se inclinaban hacia campos culturales propios de las clases bajas, con sectores que habían emergido durante los ochenta, como los punks de barrio bajo y las pandillas conocidas como "chavos banda", sectores que expandieron la noción de lo popular en nuestro país, ya no como figura ornamental de la retórica ilustrada o de izquierda, sino reconocidos como un conjunto de sujetos activos, con voz propia.

Allen destaca otra característica de las revistas de artista extranjeras: el hecho de que estas se definían en contra de los medios de comunicación convencional, tanto en la forma como en el contenido, especialmente en relación con los medios culturales, pero sobre todo porque, según escribe, "no eran secundarias o suplementarias a otro tipo de espacios alternativos e instituciones sino que se hallaban profundamente entretejidas con las nuevas economías culturales que dichas instituciones ayudaron a dar origen". ${ }^{41}$ Además, afirma, las revistas de artista no seguían criterios lucrativos, sino culturales, artísticos, sociales y políticos ${ }^{42}$ Por lo mismo, estas revistas insistían en echar mano de condiciones y criterios diferentes para evaluar el arte. Evidentemente La PUSmoderna compartía todas estas perspectivas descritas por Allen. Muchas de estas características de las revistas de artista descritas por Gwen Allen eran comunes también a las revistas estadounidenses underground de los años 1960-70 . De hecho, según Allen, las revistas underground sirvieron de modelo para las revistas de artista. ${ }^{43}$

\section{La prensa underground estadounidense}

En efecto, a diferencia de las flamantes revistas del mainstream cultural estadounidense, hechas con materiales caros, las revistas de artista al igual que las underground o contraculturales estadounidenses, utilizaban formatos nada pretenciosos como el mimeógrafo o el papel periódico: "casi siempre sin dinero, ellas se apoyaban en becas, publicidad exigua, e ingresos por suscripciones, además de trabajo intelectual de sus editores y colaboradores frecuentemente no retribuido". ${ }^{44}$

Los Angeles Free Press, fue de las primeras publicaciones underground en los sesenta. En esa época, según escribe Abe Peck, las publicaciones underground publicaban noticias sobre manifestaciones, reseñas de rock y cómics contraculturales. A pesar de que la prensa underground criticaba la economía monetaria, sí publicaba anuncios de papeles para liar cigarros, publicidad de discos LP's y de pantalones de mezclilla. Según describe Abe Peck, los reporteros de los periódicos establecidos llevaban credenciales de prensa expedidas por la policía para identificarse, mientras que los diarios underground debían imprimir tarjetas de prensa falsas para proteger a sus reporteros durante las manifestaciones. ${ }^{45}$ Por último, de acuerdo siempre con Peck, los contenidos 
de la prensa underground incluían chistes internos, documentaban las relaciones entre los colaboradores y editores, así como las diferencias de opinión entre ellos, a partir de las cuales se disolvían amistades, se cambiaban colaboradores o editores. ${ }^{46}$ Características que también compartía La PUSmoderna.

\section{La noción de independencia}

31 La PUSmoderna reivindicó su independencia de criterio en los contenidos, pero también en la propia gestión, producción y edición del medio. Tanto para La PUSmoderna, como para La Regla Rota, la noción de independencia como praxis definió al propio proyecto y su sentido. Antes que una revista contracultural, alternativa, underground, o de artista, La PUS se veía a sí misma como una revista independiente. La PUSmoderna y La Regla Rota se desmarcaron de las revistas culturales que recibían subsidio de alguna institución como era común en la tradición editorial que iría de Los Contemporános hasta Plural y, en los ochenta, hasta La Orquesta, Infame Turba, Casa del Tiempo, entre otras. De acuerdo a Octavio Paz: "Las revistas literarias mexicanas, hasta la aparición de Vuelta, han sido subvencionadas o publicadas por una institución pública o por una empresa periodística. La única excepción fue Letras de México, editada por Octavio G. Barreda". ${ }^{47}$ Por su parte, John King consigna una excepción más a la norma descrita por Paz, refiriéndose a la revista independiente S.Nob, dirigida por el escritor Salvador Elizondo y patrocinada por el productor de cine Gustavo Alatriste, si bien sólo publicó siete números. ${ }^{48}$ En estas circunstancias, la mayoría de las jóvenes revistas culturales o literarias convencionales a lo largo de los años, buscaba llamar la atención de los grupos ya establecidos para insertarse en un sistema literario preexistente, incluso mediante la ostentación de alguna relativa diferencia, pero siempre manteniendo la aspiración de alcanzar el reconocimiento y la integración en dicho sistema. No fue el caso de La PUSmoderna.

En 1987 Villarreal polemizó acerca de la independencia editorial de las revistas con Gustavo García, director de la revista de cine Intolerancia, cuestionando la dependencia de las revistas con el Estado: “¿En realidad satisface alguna necesidad La Orquesta? ¿Ha sido capaz en un año de crear su propio público? ... El futuro es crudo y previsible: $L a$ Orquesta dejará de existir simple y llanamente cuando le suspendan el subsidio y, lo que es peor, nadie la va a extrañar (como ya nadie habla de Diálogos) [...] ¿Qué sucede con esta megamafia de cantina que no ha sido capaz de edificar un sólido proyecto colectivo a la altura de sus capacidades individuales sin la complacencia vanal del Estado?" ${ }^{49}$

Al desmarcarse de todas estas revistas, La PUS asumía su ostracismo como un gesto contestatario, desafiante ante las revistas que se insertaban en el gran mercado y se atrevían a considerarse "independientes", como sería el caso emblemático de Vuelta, ${ }^{50}$ a la cual Villarreal consideraba subsumida a sus anunciantes. También es cierto que, a pesar de su marginalidad radical, para La PUS el suplemento cultural Sábado, del diario Unomásuno, dirigido por Huberto Bátis, fue un espacio importatntísimo, casi un aliado. En este sentido, vale la pena recordar lo que dice John King acerca de la importancia de los suplementos culturales en el mundo editorial: "Los suplementos culturales de periódicos y revistas ofrecieron empleo a los escritores, un público para sus ensayos, poemas o cuentos más amplio que cualquiera de las revistas pequeñas -audiencias de decenas de miles en lugar de los, cuando mucho, mil o menos lectores-, así como la 
posibilidad de difundir sus libros entre ese amplio público" ${ }^{51} \mathrm{El}$ suplemento Sábado apoyó de esta forma a la gente de La PUSmoderna, y también a la de la revista Moho.

En realidad, La PUSmoderna provenía de una larga tradición de prácticas culturales marginales o descentradas, que fueron producto de la crisis de legitimidad de las instituciones a partir de 1968. Crisis que seguiría profundizándose y diversificándose en distintas posturas dentro del campo del arte, del rock, del cine, el video, de la literatura y de las publicaciones, a lo largo de los lustros. Y en efecto, a finales de los ochenta, muchas de las experiencias independientes se desinteresaron por emplazar al Estado $\mathrm{y}$, en cambio, lo dejaron prácticamente de lado como interlocutor potencial, pasando a autoconcebirse ya como proyectos o experiencias alternativas, subterráneas, independientes o autogestivas. En otras ocasiones, se asumían incluso como simples negocios diminutos, apenas autosustentables. No hay una evolución progresiva respecto a esta diversidad de posturas, mucho menos un desarrollo teleológico. Cada postura fue, más bien, producto de la cotidianeidad singular de cada una de las comunidades de artistas y productores culturales dentro de los diferentes campos disciplinarios, enfrentados a sus propias circunstancias. Esta especificidad les llevó casi siempre a emprender sus proyectos con recursos propios, por la sencilla razón de que, simplemente, no había de otra. Es decir, la independencia dentro del subterráneo de los ochenta fue, más que un movimiento cultural programático, una serie de actitudes coincidentes ante la carencia fatal, absoluta, de cualquier otra opción. Esta sensación inerme ante la fatalidad inamovible de un mundo cerrado, obligaba a los protagonistas a ejercer una práctica basada en los propios recursos por mínimos que fueran, pero que, en algunos casos, evolucionó hacia la reivindicación de la propia autonomía. Podrían registrarse los cambios en las nociones de independencia, por ejemplo, desde asumir la independencia como una fatalidad, hasta reivindicar expresamente la propia autonomía o, incluso, llegar a concebir a esta última como una facultad negociadora ante distintos frentes, incluido el del mercado y las instituciones, tal como sucede de manera estable, incluso canónica, hoy día. En el caso de La Regla Rota y La PUSmoderna, ambas reivindicaron siempre la autogestión, si bien la segunda logró obtener un premio para revistas independientes y una beca del Fondo Nacional para la Cultura y las Artes.

En suma, a lo largo de los ochenta había en la subterraneidad distintas nociones de independencia que, en algunos casos, podían tener una intencionalidad autogestiva, en otros estarían más cerca de una pequeña empresa convencional; o bien, a veces se mostrarían proclives a la formación de colectivos culturales espontáneos. Todas estas prácticas tendieron a tejer una red de redes descentradas. Sea como sea, desde principios de los setenta, pero sobre todo en los ochenta, fue construyéndose un universo de prácticas culturales subterráneas con distintas posturas hacia el Estado y las industrias culturales, así como hacia los sistemas culturales establecidos. Al final de los ochenta, la ciudad era como un país de mosaicos atomizados e invisibles, donde las diversas escenas o comunidades subterráneas no siempre se tocaban. Estos submundos, ya conformados por varias generaciones, comenzaron cada vez más a encontrarse entre sí en diversos puntos. Uno de ellos fue la revista La PUSmoderna.

\section{Posmo chic o posmodernidad purulenta}

Pero volvamos al origen de La PUSmoderna (1989). Eran los días de la posmodernidad, no sólo como filosofía sino también como una impostada versión fashion local, asumida 
como sabor de moda o color de temporada. ${ }^{52}$ De ahí que la revista La PUSmoderna se desmarcara, desde su nombre, respecto de la moda posmoderna y, en cambio, se ubicara en la calle mexicana como escenario de una sempiterna "posmodernidad", es decir, de una modernidad paradójica, tan heterodoxa como contradictoria, no canónica y, como tal, siempre difícil de asir desde los códigos metropolitanos.

37 A la frivolidad "posmo", como desplante chic, La Pus oponía la irritada frivolidad como una forma de crítica cultural. Es decir, asumía una posmodernidad de jerarquías invertidas, inclinada por lo marginal, proclive incluso hacia lo purulento, lo estigmatizado, regodeándose también en el habla callejera. Seguramente este desmarcaje del glamour de la posmodernidad importada resultó un gesto todavía más posmoderno.

En la editorial "Un rostro sin espinillas es como un cielo sin estrellas", ${ }^{53}$ la revista buscó justificar el nombre de La PUSmoderna. De acuerdo a esa editorial, la pus, en minúsculas, es la representación de los fluidos internos, ocultos, subterráneos, sucios: "lo que no fluye se pudre". ${ }^{54}$ La pus representaba "la contradicción" como estado primigenio y crítico. La otra acepción del vocablo pus remitía al habla callejera, como sustituto del pues; es decir, aludía al campo semántico propio del territorio de lo antiacadémico, reivindicando la lengua viva, el lenguaje abierto: "Con el pus se pregunta o se abren puntos suspensivos [...] Y con el pus también se responde." ${ }^{55}$

Inevitablemente hija de los tiempos posmodernos, al fin y al cabo La PUS y sus escenas optaron por invertir las jerarquías estéticas, éticas e intelectuales: la vinculación con el planeta a través de la economía informal en esos días previos a Internet; la tendencia reivindicativa o no- de la autogestión como crítica pragmática, de facto, contra la política cultural asistencialista y clientelar del Estado mexicano (de partido hegemónico).

\section{La autonomia y la independecia en la subterraneidad}

En los años ochenta las escenas subterráneas o emergentes relacionadas con el rock, el arte y las publicaciones periódicas, no se habían institucionalizado en los circuitos de mercado local ni global, por lo que, en su gran mayoría, sus estrategias de producción y diseminación se regían aún por la lógica de la economía subterránea que, sin embargo, dialogaba desde otro sitio y de otra forma con lo global. Sería hasta finales de los noventa que las escenas subterráneas saldrían de su relativo ostracismo para terminar articulándose a circuitos de la gran industria cultural local. El Festival Vive Latino de rock comenzaría hasta 1998, la feria internacional de arte contemporáneo Zona Maco en 2004, El Festival Internacional de Cine de Guadalajara (que comenzó con el nombre de Muestra, en 1986) despegó en el mercado global hasta $2005 .{ }^{56} \mathrm{El}$ inicio de estos festivales marca un cambio en la articulación con las producciones culturales de sus respectivas escenas.

41 Por su parte, si las políticas culturales estatales de la década de los ochenta por lo general consideraban que debían subsidiar a la cultura protegiéndola de la perniciosa injerencia del mercado, ${ }^{57}$ a partir de 1990 el Estado mexicano implementó un impulso "modernizante" para la industria del espectáculo con el otorgamiento de la concesión del Palacio de los Deportes al corporativo OCESA ${ }^{58}$ (octubre 1990) y con la creación del Fidecomiso del Auditorio Nacional, que ejercería a partir de mayo de 1991 un modelo de 
gestión cultural tripartita ${ }^{59}$. A partir de 2003, el Estado mexicano realizaría la feria de artes escénicas Puerta de las Américas, un mercado que implicaba pensar al universo cultural ya como un entramado de empresas creativas independientes del Estado, a las cuales la feria debía ayudarles a articularse con el mercado global y nacional.

En cambio, Rogelio Villarreal y Ramón Sánchez Lira buscaron financiar su proyecto mediante las ventas directas de la revista, las inserciones de publicidad, las becas de CONACULTA en un momento dado, y el apoyo de artistas y amigos que colaboraron gratuitamente, además de la alianza con Donnadieu (por cierto, el Bar Nueve no era en sí mismo autogestivo; se trató de una discoteca gestionada convencionalmente, salvo porque estaba dirigida principalmente a la comunidad homosexual). Nunca lograron resultados pecuniarios solventes, ni alcanzaron la claridad suficiente sobre cómo estructurar internamente estas estrategias para conseguir sus fines. Por lo anterior podemos concluir que, aún sin proponérselo, La PUSmoderna se rigió bajo una lógica de operación y prácticas semejantes a la de las revistas underground de la contracultura estadounidense de los sesenta. Reflejó el tránsito de las escenas subterráneas del periodo hacia una nueva institucionalidad, inscrita ya dentro de los circuitos del mercado global. Además, La PUSmoderna fue un espacio en sí mismo, desdoblado en un espacio metafórico y otro arquitectónico: el soporte en papel, por un lado, y el Bar Nueve, por el otro; lo cual la convirtió en una plataforma de encuentro de generaciones, escenas y disciplinas, a la manera de un espacio de exhibición como los muchos otros espacios alternativos que se abrieron en el periodo. Con esta característica irreductible, la revista reflejó, tanto como ayudó, a conformar las escenas subterráneas del periodo, convertida en un lugar de irradiación que marca también el momento de una dispersión hacia nuevas prácticas o economías. Las páginas de la revista registraron, incluso, la emergencia de un nuevo agente cultural, el curador.

Por último, si la apertura política comenzada con el presidente Luis Echeverría (19701976), y las estrategias de Carlos Salinas de Gortari (1988-1994), abrieron la posibilidad de participación de varios sectores sociales activados desde el movimiento estudiantil de 1968, esta apertura no incluyó a los nuevos agentes culturales de las escenas subterráneas que desde los sesenta habían surgido, conformadas por una serie de circuitos de producción y diseminación cultural que tuvieron que emprender por sí mismos sus propios proyectos culturales a veces reivindicando su independencia o su autonomía, regidos en su mayoría por la lógica de la economía informal, constituyendo redes sociales conectadas de manera presencial, dejando de lado al Estado como interlocutor, pugnando por su derecho a participar en la sociedad mexicana, reivindicando su especificidad, su diferencia sexual, cultural, o artística. La evolución de estos procesos no se consolidó en un sin número de circuitos culturales de pequeña economía, autogestivos, sino que se conjugarían con las industrias culturales del neoliberalismo global, inmersos ya en otros paradigmas de producción cultural en el país. 


\section{NOTAS}

1. "Remakes", en La era de la discrepancia. Arte y cultura en México, 1968-1997, México, Universidad Nacional Autónoma de México, 2006, p. 406

2. John McMillian, Smoking typewriters. The Sixties Underground Press and the Rise of Alternative Media in America, New York, Oxford University Press, 2011, p. 37.

3. Olivier Debroise, "Me quiero morir", en La era de la discrepancia. Arte y cultura en México, 19681997, México, Universidad Nacional Autónoma de México, 2006, p. 278.

4. El propio editor de la revista, Rogelio Villarreal, consideraba que La PUSmoderna era la continuación de La Regla Rota; cf. Rogelio Villarreal, Sensacional de contracultura, México, Ediciones Sin Nombre, 2009, p. 51.

5. Gerald Raunig, "La industria creativa como engaño de masas", en Producción cultural y prácticas instituyentes. Líneas de ruptura en la crítica institucional, Madrid, Traficantes de sueños, Mapas 20, 2008, p. 37.

6. Vania Macías consigna que Art Deposit surgió en 1995 bajo la iniciativa de Stefan Brüggemann y Edgar Orlaineta, ambos alumnos de la escuela de Pintura y Escultura La Esmeralda. Vania Macías, "Espacios alternativos de los noventa", en La era de la discrepancia. Arte y cultura en México, 1968-1997, México, Universidad Nacional Autónoma de México, 2006, p. 369.

7. Para más detalles sobre una caracterización de la forma de operar subterráneamente, puede verse José Luis Paredes Pacho, "Un país invisible. Escenarios independientes: autogestión, colectivos, cooperativas, microempresas y cultura alternativa”, en Francisco Toledo, Enrique Florescano y José Woldenberg (coord.), Cultura mexicana: revisión y prospectiva, México, Taurus, 2008.

8. Germán Arzubide List, “Borges Rojo”, La Regla Rota, n4, primavera de 1987, México, p. 32.

9. Rogelio Villarreal, Sensacional de contracultura, México, Ediciones Sin Nombre, 2009, p. 131.

10. "Infrarrealistas", La era de la discrepancia. Arte y cultura en México, 1968-1997, México, Universidad Nacional Autónoma de México, 2006, p. 214.

11. Mónica Meyer, “Rubén Valencia (1949-1990)”, Sección Tiradero, La PUSmoderna, n², enerofebrero 1990, México, p. 65.

12. El término "neomexicanismo" relacionado con las artes plásticas, fue introducido por Teresa del Conde en 1987, cf. Josefa Ortega, "Introducción”, en ¿Neomexicanismos? Ficciones identitarias en el México de los ochenta, México, Museo de Arte Moderno, 2011, p. 18. Fuera de esta estabilización de la categoría, la palabra puede ser entendida como la tendencia a incorporar expresiones que parten de nociones de localismos reconfigurados, en oposición al "neomexicanismo" en la plástica como una corriente ya codificada.

13. Víctor Roura, “Aguacates, Rock'nRoll y una Botellita de Jerez”, La Regla Rota, n², verano 1984, México, pp. 13-17.

14. Danzas de inspiración indígena.

15. Periódico popular amarillista.

16. Forma popular de hablar con doble sentido, casi siempre con carga sexual y sexista.

17. El héroe más popular de la lucha libre mexicana.

18. Pedro Núdelman, "Escenario del rock Chilango", La Regla Rota, $n^{\circ} 4$, primavera de 1987, México, p. 79. Rolando Ortega y José Luis Paredes Pacho escribieron en 1987 este artículo bajo el heterónimo de Pedro Núdelman.

19. Rogelio Villarreal, Sensacional de contracultura, México, Ediciones Sin Nombre, 2009, p. 132.

20. Villarreal, Sensacional de contracultura, p. 138.

21. Comunicación personal de Rogelio Villarreal con José Luis Paredes. 
22. Jose Luis Paredes Pacho, Rock mexicano, sonidos de la calle; México, Aguirre Beltrán Editores, 1992, pp. 16-19

23. Cuahtémoc Medina, "Pánico recuperado", en La era de la discrepancia. Arte y cultura en México, 1968-1997, México, Universidad Nacional Autónoma de México, 2006, p. 94.

24. En su polémica con Gustavo García, editor de la revista independiente de cine Intolerancia, Villarreal afirmó que no se podía "negar la importancia del reventón -y sobre todo los que hemos organizado desde hace casi un año- en el nutrido intercambio intelectual, vivencial, etílico y cachondo entre cientos de personas relacionadas de un modo u otro con lo más fresco, propositivo y audaz de la cultura en México"; Rogelio Villarreal, Sensacional de contracultura, México, Ediciones Sin Nombre, 2009, p. 23.

25. José Luis Paredes Pacho, El derecho a la Fiesta. Rock y autogestión en la Ciudad de México, 1980-1995, México, Tesis para obtener el título de Licenciado en Historia, Escuela Nacional de Antropología e Historia, 2004.

26. Cuauhtémoc Medina, "Pánico recuperado", en La era de la discrepancia. Arte y cultura en México, 1968-1997, México, Universidad Nacional Autónoma de México, 2006, p. 94. Tanto La Regla Rota, como La PUSmoderna, al igual que el mencionado grupo de Botellita de Jeréz, mostaron cierta fascinación con la estética de la prensa amarillista. Villarreal publicó en sus revistas artículos relacionados con ese tema, por ejemplo el artículo, Carlos Monsiváis, "La Nota Roja: de tres tiros que le dio nomás cinco eran de muerte!”, La Regla Rota, nº , primavera de 1987, pp. 18-22.

27. Rogelio Villarreal, Sensacional de contracultura, México, Ediciones Sin Nombre, 2009, p. 23.

28. En entrevista con Carlos Martínez Rentería, Villareal menciona retrospectivamente que le llegaban revistas de Lima (Macho Cabrío), de Buenos Aires (Cerdos y Peces, o La Selva Subterránea), y de Madrid (La Luna, Madrid me Mata): "Había una erupción paralela, compartíamos una sensibilidad muy de los ochenta, digamos incipientemente posmoderna", Rogelio Villarreal, Sensacional de contracultura, México, Ediciones Sin Nombre, 2009, p. 132.

29. Abe Peck, Uncovering the sixties. The Life and Times of the Underground Press, New York, Citadel Underground/Citadel Press Book/Carol Publishing Group, 1991; pp. xiv-xv.

30. La PUSmoderna, $\mathrm{n}^{\circ} 4$, primavera 1992, p. 1.

31. Gwen Allen, Artists' Magazines. An Alternative Space for Art, Cambridge, Massachusetts, The MIT Press, 2011, p. 71.

32. Allen, Artists' Magazines, p. 9.

33. "Aspen suggest, in ways that resonate powerfully [...] the transformation of the magazine from a two-dimensional bound object, into a three-dimensional exhibition space"; Gwen Allen, Artists' Magazines. An Alternative Space for Art, Cambridge, Massachusetts, The MIT Press, 2011, p. 9.

34. Villarreal refiere que fue en La PUSmoderna número 1. Comuniación personal de Rogelio Villarreal con José Luis Paredes, 3 de marzo, 2013.

35. Sin caer en las fotocopias engrapadas de los fanzines mexicanos a la sazón.

36. Allen, Artists' Magazines, p. 72.

37. Allen, Artists' Magazines, p. 7.

38. Allen, Artists' Magazines, p. 73

39. "Artists did not merely use Aspen to document and distribute their work; they also explored the magazine as a temporal, interactive medium", Gwen Allen, Artists' Magazines. An Alternative Space for Art, Cambridge, Massachusetts, The MIT Press, 2011, p. 9.

40. Allen, Artists' Magazines, p. 7.

41. Ibid.

42. Allen, Artists' Magazines, p. 8.

43. Allen, Artists' Magazines, p. 7.

44. Allen, Artists' Magazines, p. 8.

45. Abe Peck, Uncovering the sixties. The life and times of the underground press, New York, Citadel Underground/Citadel Press Book/Carol Publishing Group, 1991, pp. xiv-xv. 
46. Gwen Allen, Artists' Magazines. An Alternative Space for Art, Cambridge, Massachusetts, The MIT Press, 2011, p. 8.

47. Octavio Paz, “Antevíspera: Taller (1938-1941)”, Vuelta 76 (marzo de 1983), p. 12, citado en John King, Plural en la cultura literaria y política latinoamericana. De Tlatelolco a "El ogro filantrópico", México, Fondo de Cultura Económico, 2011, p. 18.

48. John King, Plural en la cultura literaria y política latinoamericana. De Tlatelolco a "El ogro filantrópico", México, Fondo de Cultura Económico, 2011, pp. 62-62.

49. Carta a Gustavo García aparecida en "La escalera y la hormiaga", Sábado, Suplemento de Unomasuno (26 de julio de 1987), reproducida en Rogelio Villarreal, Sensacional de contracultura, México, Ediciones Sin Nombre, 2009, p. 28.

50. Después de diez años de ser una asociación civil, la revista Vuelta anuncia en julio de 1986 su constitución como la empresa Vuelta S.A. de C.V.; cf. Malva Flores, Viaje de vuelta. Estampas de una revista, Fondo de Cultura Económica, México, 2011, p. 40. Ante las críticas de que la publicación era una filial de Televisa, Malva Flores señala que estadísticamente "fueron las empresas editoriales, el gobierno, las paraestatales y el sector educativo público y privado quienes más anuncios publicaron en Vuelta, de modo que la publicidad de Grupo Televisa (391) represento sólo 9\% del total de 4,218", a lo que Krauze agrega que eso representó incluso menos del 3\% de ingresos de la revista; cf. Flores, Viaje de vuelta, p. 90.

51. John King, Plural en la cultura literaria y política latinoamericana. De Tlatelolco a "El ogro filantrópico", México, Fondo de Cultura Económica, 2011, p. 50

52. Olivier Debroise parecía coincidir: "Existe efectivamente en México una tendencia equivalente al posmodernismo norteamericano: aparentemente relacionada, tiene fundamentos substancialmente distintos -casi diría incomparables. De ahí la reticencia a emplear el término importado." Olivier Debroise, "Un Pos modernismo en México", México en el Arte, 16 (primavera 1987), http://www.arte-mexico.com/critica/od102.htm.

53. Paredes Pacho, "Un rostro sin espinillas es como un cielo sin estrellas", La PUSmoderna, $\mathrm{n}^{\circ} 3$, enero, febrero, marzo, 1991.

54. La PUSmoderna, $\mathrm{n}^{\circ} 3$, enero-febrero-marzo de 1991, México, p. 2

55. Ibid.

56. Antes se llamaba "Muestra de cine en Guadalajara", cambia su nombre en 2005 y un año después toma su dirección Jorge Sánchez. Comunicación personal de Carlos Sosa, director de la Casa del Cine Mx, 22 de mayo, 2013.

57. Marcelo Expósito describe este paradigma de la siguiente manera: La cultura era "un territorio simbólico desde el cual producir bienes inmateriales que son, en sí mismos, bienes comunes que necesitan ser protegidos de la injerencia del mercado y de la industria cultural". Marcelo Expósito, “Introducción”, en Producción cultural y prácticas instituyentes, líneas de ruptura en la crítica institucional, Madrid, Traficantes de Sueños, Mapas, 2008, pp. 19-20.

58. El Palacio de los Deportes fue inaugurado el 13 de septiembre de 1968 por el presidente Gustavo Díaz Ordaz, con motivo de la XIX Olimpiada; desde entonces fue propiedad del Departamento del Distrito Federal (el gobierno de la Ciudad de México) y, a partir de octubre de 1990, comenzó a ser manejado por el corporativo Operadora de Centros de Espectáculos, S.A. (OCESA).

59. Cf. Rafael Tovar y de Teresa, "Reunión permanente de expresiones culturales", en El Nuevo Auditorio Nacional, 1991-1994, Grupo Azabache, México, 1994, p. 9. 


\section{RESÚMENES}

La revista La PUSmoderna se convirtió en una plataforma de encuentro entre generaciones artísticas, campos y escenas culturales marginales o alternativos, a la manera de un espacio alternativo, incluso tridimencional, pero además documentó un momento de cambio en el desarrollo de las escenas culturales subterráneas de la capital de México, justo cuando esos circuitos comenzaron su proceso de institucionalización dentro del sistema de mercado mundial. La revista provenía de una larga tradición de prácticas culturales marginales o descentradas, producto de la crisis de legitimidad de las instituciones a partir de 1968, que tejieron una red de redes descentradas con distintas posturas hacia el Estado, el cual transitaba ya hacia el neoliberalismo.

The magazine La PUSmoderna became an alternative, even three-dimensional, space for the encounter between artistic generations, cultural fields and marginal or alternative cultural scenes. But it also documented a moment of transformation in the development of the underground cultural milieu of Mexico City when they began to institutionalize within the world-market system. The magazine was a continuation of a long tradition of marginal or decentralized cultural practices, resulting from the institutional crisis of 1968. This publication faced the difficult challenge of defining its relation to the cultural institutions of the Mexican State, a time in which it was adopting neoliberal policies.

\section{AUTOR}

\section{JOSÉ LUIS PAREDES PACHO}

José Luis Paredes Pacho is a Mexican musician, researcher, and curator. He is the founder of Nueva Poesía en Voz Alta (poetry festival) and Radical Mestizo, a programme of new musical rhythms as part of Festival de México. Pacho is a founder member of Mexican rock band La Maldita Vecindad y los Hijos del Quinto Patio, where he played the drums for eighteenth years. His academic work focuses on the history of rock music and counterculture movements in Mexico. Since 2012, Pacho is the director of Museo Universitario del Chopo, contemporary art gallery of the National Autonomous University of Mexico. He teaches sociology of pop music at the Faculty of Social and Political Sciences at UNAM in Mexico City. 